\title{
Psycho-semiotic Approach \\ in Psycholinguistics Analysis \\ of Verbal Material as a Means \\ of Recreation of the Individual Picture \\ of the World of Man
}

\author{
Marina W. Novikova-Grund* \\ Russian State University for the Humanities \\ 6 Miusskaya ploschad 6, Moscow, 125993, Russia
}

Received 01.09.2016, received in revised form 13.09.2016, accepted 10.01.2017

\begin{abstract}
In the modern psychological tradition there exists a dramatic disparity between the experimental probative research and the psychotherapist practice. It is connected with the fact that such most important elements in existential and humanistic psychotherapy of existence as "the picture of the world of man", "freedom", "loneliness " etc. are semantically uncertain concepts and therefore they are inaccessible for experiment checkup with the use of the traditional mathematical methods. However their formalization as well as their use in practice is possible. With the help of psychosemiotic methods it became possible to prove that the picture of the world of a human being is not a metaphor but it does exits in reality and is reflected consequently on the texts both written and oral which are generated by this human being. Analyzing the texts with the help of the specially created formal procedure it became possible to recreate the model of the picture of the world of the author of these texts while the formalization brings to the minimum the plurality and the arbitrariness of the interpretations whereas the reliability is checked with the help of the easy mathematical method with the use of combinatorics. As a result it became possible to detect omissions and in a number of cases to reconstruct them (with the data precision), which apart from the theoretical interest opens up new productive strategies in psychotherapy.
\end{abstract}

Keywords: psycholinguistic, semiotics, syntactic structure, paradigmatics and syntagmatics, existential problems, plot structure, psychotherapy, preterition.

DOI: 10.17516/1997-1370-0045.

Research area: philology; psycholinguistics.

From what point of the semiotic universe do we look at the world?

Following the logic of Heidegger the picture of the world is by all means somebody's view of the world. Consequently, subjectivity is the immanent property of something that is meant and the semantic component of the meaning of the picture of the world. The picture of the world on the whole and its components have been in the focus of attention of different psychotherapist

(c) Siberian Federal University. All rights reserved

* Corresponding author E-mail address: dmitrinus@gmail.com 
aspects - gestalt-therapy, humanitarian, existentialist approaches and quite a number of others.

However the semantic uncertainty and the semantic polysemy of the interpretation of these issues was such that researches were compelled to refuse of the immediate empiric and experimental investigation as the usual statistic methods could not be applied to them, and in a number of cases when translating from one European language into another (e.g. the problem of Angust) also of the comparison of similar constituents which are used in the framework of different aspects (compare 'contact' in gestalt and 'closeness' in existential psychology).

"The Tower of Babel" which launched the differentiation of the languages of description which now have become stable in a number of the existing approaches, was presented in our view by a number of researches in the field of philosophy of the existential type (Kierkegaard, Husserl and particularly Heidegger, Gadamer and also Jaspers, Sartre and others) who changed the paradigm in the sphere of humanities in the $20^{\text {th }}$ century in principle, but with all that they wrote in a complicated manner which presupposed many meanings, so that the plurality of the interpretation was a direct result of the depth of understanding of the human soul on the one hand and of the kind of narrating about it on the other.

It is with the initiation of the "existential system of the coordinates" which did not reject the Cartesian one but only covered another field of potential problems that there should be found the final distinction between the theoretical scientific and psychotherapist intentions of the research in psychology. The theoretical research has been defined in the natural way as belonging to the objective "de Carte" system of coordinates in which the picture of the world consists of " the objects observed" and "the observer" who is separated from them, while the most varied psychotherapist aspects are found as included somehow or other in the subjective "non de Carte" coordinates in which every "observer" from the multitude of the "observers" would observe the objects in his own vision from which he is not separated, so that the act of observation has an impact on him and changes him . This fact demanded addressing the method of acquiring the subjective picture of the world (to be exact, the subjective views of the world of different people), which appeared extremely beneficial with regard to understanding the problems of a certain human being, it also allows to take a look at reality through a person's eyes. But this new subjective approach had also another side to it: remaining subjective and being in motion and in a state of "fluidity", it could not be described with the standard mathematic meta-language, the mathematical objectivity could either be not used at all or a new mathematical meta-language had to be created.

\section{The observer and the object observed}

The existential approach to psychology could be naturally become another area of the realm of neoclassical scientific approaches. However there was one important circumstance which resisted this practical step.

Instrictneoclassical approaches the observer and the object observed are of different nature. A physicist observing elementary particles is not an elementary particle himself. In using the existentialist approach the observer and the object observed are people on the same footing who have their own subjectivity. It makes practically impossible to attain some "instrumentality" using tautology: a psychologist investigates the inner world of man using as an instrument his own inner world which he is obliged to know inside out - if it does not happen then he does not have any other instrument but himself. One 
of the ways to get him free from this logical nook can be the introduction of an artificial object -mediator between the inner worlds of two people. It will be complicated enough to suit the homomorphic reflection of different, and it is most desirable, of any inner worlds and at the same time "sufficient" enough, the one which can be observed and discreet to function as an instrument. This is a verbal product, a text in its general semiotic understanding. It is really true that all the notions and emotions about the inner world of another person can be received almost exclusively through the verbal product of this person.

The tradition of the investigation of the verbal sphere is extremely profound though generally it is limited by two models." The psychological model" focuses on what the given person is saying without paying much attention to the modes of "speaking".

In the developed system of "linguistic models", on the contrary, all attention is given to the "modes of speaking", but there is no reflection why this given person has chosen from the multitude of ways of saying something this particular mode.

But at the same time it should be acknowledged that the "psychological" and the "linguistic" approaches are coordinated with each other as paradigmatics and syntagmatics. (Jacobson). The linguistic interest to the language boils down in the broadest sense to the codification and inventarization of all linguistic phenomena which exist or can be, - that is to the building of the paradigm. The physiological interest in the broadest sense, on the contrary, is directed to the selection and combination of the concrete linguistic phenomena- that is to the building of the syntagma.

In the present research a number of consistent attempts of the complex and well thought search of syntagmatic factors is undertaken which predetermine the concrete choice and combinations which refer to the sphere of psychology with repeated address to the linguistic paradigm. It made it possible to go beyond the limits of the opposition of the "classical" and "non-classical" approaches applying both to the observed and the observer the same instrument the generated text.

\section{What is there in common \\ between grammatical forms, syntactic structures and non-healing traumas}

Pre-hypothesis of the picture of the world.

In the process of the hypothesis (or hypotheses) which had to be checked the following had to be formulated:

The picture of the world (in its existential understanding which was suggested above) exists not as a metaphor or as a theoretical constituent but as a means which an individual uses to organize his "reality", that is his life and emotional experience.

The picture of the world of every individual is unique though some fragments of the picture of the world of different people may coincide. The picture of the world of an individual person is reflected on any text generated by him, oral and written, spontaneous and edited, it finds its reflection in a multitude of linguistic choices in the framework of the variation which his native language offers him.

In other words, the unique picture of the world of an individual is reflected in his unique linguistic picture of the world.

However, the theoretical assumptions formulated above aroused serious methodological difficulties. These difficulties arose not only because of the huge volume of information but also because of the differences in the information about the personality of the author which the researcher could gather from the multitude of 
cases of observation of his texts in the course of the psychotherapist contact.

The greatest difficulty arose of the vague character of the concepts which has to be accepted and somehow or other to be managed with when a therapist is doing his practical work. This vagueness does not allow separating them from the general continuum of empiric observations which could be checked in the experimental way.

That is why before advancing the main hypothesis it seemed convenient to use the logical instrument of pre-hypothesis. The pre-hypothesis does not contain strictly absolute complete formulation but it presupposes the most important directions for further research. In the process of work with the senses of pre-hypothesis the process of finding, making precise and supplying terms to those words which express the senses of the pre-hypotheses is taking place. As a result of this formal-semantic process the pre-hypothesis is transformed into the correct hypothesis which is checked by strict methods.

The formulation of the pre-hypothesis was presented in the following way:

The mental reality of a human being in some aspects has regular reflection in the texts which he generates. For the convenience of further work it was symmetrically transformed.

The investigation of the regular features of the texts generated by a human being allows to arrive at conclusions about some aspects of his mental reality. It is easy to see that it is a completely symmetrical transformation which permits to solve them in a regular order: from the formal properties to their meaning; it focuses attention just on that segment of the mental reality of a human being which is immediately reflected in his verbal activity and which can be hardly accessible by any other methods.

The result of the checking of the prehypothesis was a precise definition of uncertain ideas about some aspects of "mental reality" which opens up the possibility to consider the hypothesis proper.

\section{The strategy of checking up the hypothesis}

It would be methodologically incorrect to presuppose the concrete character of these "some aspects of mental reality". It would be natural to expect as a starting thesis the approach from the point view of psychology that the text reflects certain personal traits of its author. It would open up the possibility for a relatively simple experimental check-up. For this just a number of personal traits could be accidentally chosen, then a control group with these traits could be selected, then a control group of people in which these traits are not expressed could be organized, and then it could be found whether there is correlation of personal traits of the people who are experimented on with the particulars of their text. However the effectiveness of this approach arouses serious doubts. Even if a number of traits could be coordinated with the particulars of the texts, a number of questions about the full list of personal traits and the list of the particulars of the text could not be fully exhausted. That is why to act by choice would mean limiting the possibilities of receiving information about "mental reality" of a human being. Then we would silently agree with the impossibility of absolutely new knowledge, and we could count only on making precise the information which we have already received due to the plurality of empiric observations. That is why a decision has been taken to refuse of the approach to the problem from the point of view of the peculiarities of a human being. Because generally we might discuss not the personal characteristics as for example such as the character of emotional and life experience or the specific character of the communicative relations between the observed person and the one who is doing the experiment, 
or some other factors which are inaccessible for a priori suppositions. Instead preference has been given to the approach to the problem from the point of view of the particulars of the text. This decision was implemented according to the following plan.

\section{Transition from pre-hypothesis consisted of five stages:}

(1) creation of the Standard List of the regularly repeated particulars of the texts of concrete human beings;

(2) structuring of the particulars observed and their coordination from the point of view of their semantics and formal properties;

(3) creation of the supposition about the concrete particulars of the mental reality of a human being which are reflected in them and change of these factors by the vague subjective concept of "mental reality".

(4) reformulation of the pre-hypothesis into the hypothesis by way of changing in the formulae: "The mental reality of a human being in some aspects" has regular reflection in the texts which he generates, uncertain concept "the mental reality of a human being in some of its aspects" in definite and concrete concepts and terms which supposedly could be seen behind the found concrete factors.

(5) transition from precise reformulation of the pre-hypothesis into the hypothesis attached to the second stage of the investigation, that is to its check up.

The approach to the formulation of the hypothesis with the help of the additional stage pre-hypothesis - excluded a priori guesswork in relation to the mental life of concrete human beings, and these events find the regular reflection in their texts. In the course of the work with the pre-hypothesis there were 3000 pairs of texts of the text techniques (TT). Text technique is a special diagnostic technique in the framework of which a human being is offered to write two texts to the especially formulated topic: the first one is in the first person, the second is written by an "antipode", that is an imagined personality which is opposed to the author of the text. In the texts of the text techniques there were repetitions which were later written down into a Standard List of the repeated elements of the text.

\section{Standard List of the repeated elements of the text}

The basis of the Standard List was compiled of those text elements which were regularly repeated in the texts of the text techniques by different authors and which were used with sufficient effectiveness in psychotherapist practice (e.g. Novikova-Grund). The repetitions were distributed according to the levels: the plot level, the composition level, the semantic level, and the syntactic level. The list of the elements of different levels which pointed out the regular repetition in the texts of different people included the following points:

The morphological indicators of the grammatical tense forms: the use of the past tense in the text which testified to the address of the author cause-effect links (on the subconscious level "when" and "for that particular reason" are indistinguishable); the use of the forms of the present tense testified to the emotions in connection with the event which is happening here and now; the use of the forms of the future tense testified to the planning, delaying or avoiding an action.

The deep-syntactical structures making the opposition of the active against the passive. The constructions with agent (the word which names the one who is committing an action according to his will), testified to being responsible (I went, I thought, I said). Non-agent constructions which either did not have the grammatical place for the agent or the agent was changed 
for the metaphorically animated non-alive and that is why being an object devoid of will, the testified to being irresponsible for an action and delegating this responsibility to another personage of the text - or, what happens more often to unplanned acts, destiny or such like. (it occurred to me, I managed to say, it seem to me). Thus there was found the godly "kairos" among the actors. It was sensible to interpret the absolute preference by the author of agent constructions as "liberty". Accordingly the nonagent constructions confirmed the "non-liberty" of the author.

The semantic level was presented by inner and outer predicates. The outer predicates describe a situation which appeals to the eyesight and to the ability of hearing; the situation is accessible to the observer who is outside the situation and who is not its participant (he ran, he shouted). The inner predicates describe the situation which does not appeal to any senses; this kind of situation is inaccessible for observation from the outside and is known only to the participant of the situation (I thought, I wanted, I got frightened). The preferences, avoidance and combination of inner predicates in the text reflected the presence or the absence as well as interrelation of "the inner world" and "the outer world" of the author of the text.

On the compositional level the analyst considered the number actors (personages) in the text. In the researched texts there were cases free of actors altogether ("A great film. Wonderful pyrotechnical effects" - the memories of mentally ill person); there were texts in which there was only one personage, and that testified to his extreme egocentric position of the author. The number of the actors as well as their characteristics with the help of agent and non-agent constructions, as well as outer and inner predicates described "loneliness" or "non-loneliness" of the author of the text.
The plot level considered the plot repetitions which will be described further on.

\section{The formulation of the hypothesis and its checkup}

After the creation of the Standard List it became possible on the basis of the observed repetitions of different levels to formulate a hypothesis.

Pre-hypothesis: the mental life of a human being is reflected in the texts which he generates. $\Rightarrow$

$\Rightarrow$ The hypothesis: the text generated by every concrete human being irrespective of his will and intentions contain on the linguistic level the reflection of the fragments of his existential picture of the world.

The following fragments of the existential picture of the world of a concrete person the following ideas can be included:

about taking on oneself the responsibility for his action or about the refusal of the action;

about the liberty to commit an action or the obligatory action under the pressure of different circumstances or other people;

about the relative actualization for him of the events of his inner or his outer world and about the special character of the objects which create these worlds;

about the causes of the events of his outer and inner worlds and in this connection about the unconscious concept of the reasons which can be represented as his guilt, responsibility, pride, powerlessness, dependence on other people or on superhuman forces;

about the preferences in the choice of the position who knows $\backslash$ rememberslexpects and event; about the preferences in the choice of the position of the participant andlor witness of the events, described in the text; about the emotions and body conditions.

The checkup of the hypothesis was performed within two stages. The first stage boiled down to 
establishing of the group similarity of the texts. For the experiment two arrays of the texts were selected.

The first comparatively small array consisted of texts TTs written by the patients of one of the critical wards of a certain Moscow hospital who got there after an attempt at suicide. Each of the patients had had over three attempts at suicide in the past.

The second array was composed of three thousand pairs of texts which were already mentioned above, they were written by men and women of different ages who did not have any formal mental diagnosis. On the basis of the Standard List 16 parameters were singled out, out of each 15 parameter had formal indicators which meant that there could not be double understanding (e.g. "the past tense" - that means the verbal endings of the past tense). One parameter which is a semantic parameter did not have a formal indicator, but nevertheless it could not be interpreted otherwise.

The texts of 15 people who attempted a suicide showed similarity in all the 16 parameters. The probability of an occasional similarity $=$ [1:(2^16)^15]-1, is utterly small. Two of the17 texts did not show similarity on the parameters either with the main array consisting of 15 texts or among them. As became clear consequently, the people who wrote these texts had not made any attempts at suicide and were under treatment in the critical ward in connection with other life circumstances. In the texts of the control group, as expected there was not a single similarity of even two texts taking into account all the 16 parameters. It allowed us to make the conclusion that the similar picture of the world of different people is similarly reflected in their texts.

Thus we propose the following hypothesis:

The texts generated by every human being, irrespective of his will and intentions on the linguistic level contains reflections of the fragments of his existential picture of the world, - it was confirmed when the group aspect was considered.

The second part of the experimental checkup of the hypothesis had to confirm or reject the individual similarity of the texts. In other words it had to be found out whether different texts written by the same person coincide with the selection of the parameters from the Standard List.

In this part of the experimental checkup structured as quasi-experiment, a possibility was researched with a purpose to establish homomorphism among some part of the sequence of text variables for different texts in structure, stylistics, and communicative intentions which were generated by the same author in different times and under different circumstances.

Four people who died long ago and that is why are inaccessible for the immediate dialog were chosen for the quasi -experimental group, they are Chekhov, Dostoevsky, Gogol and Nabokov. All the published texts of these 4 authors without any exception were used as the material. A Pseudoauthor was created as a control group, who was represented by fragments of texts of different real authors of the 19-20 centuries (patchwork blanket). It is obvious that the Pseudo-author could not have the unique individual picture of the world because he was not a human being. The procedure of comparison presupposed complete formalism and balance of the volumes.

\section{The Results of the Comparison}

The result of the investigation of the texts of the 4 real authors according to the parameters was obtaining invariables for every author and finding out regularities common for all the 4 arrays.

The general regularities, according to our view, can be extrapolated with a high probability beyond the limits of the 4 studies arrays of the texts, and they can be estimated as some "norm" which naturally may be further specified. The 
Pseudo-author revealed quantitative distinctions of the kind which could be used for any unspecified text, no matter whether it has been written by one person or compiled from different texts (the text should include over 1500 words).

\section{The fairytales of everyday conversations: plot structures}

Plot structures were not included in the Standard List of the parameters of the text because of their formalization. It was necessary to get rid of unspecified interventions and to determine correctly and to describe some fact and to make sure which particular similarity is being described and generally what should be understood by similarity in order to describe the experimental checkup of the fact of the coincidences of plot structures and moreover to discuss whether these repetitions of plot structures and their elements are connected with individual and superindividual factors (language, cultural and biological).

Two important facts should be highlighted:

a) The fact of repetition of plot structures in the texts generated by different people is so hard to explain and is so surprising that to take it as something given not trying to find some sensible explanation of the fact is sheer positivistic hypocrisy. Behind this hypocrisy there can be found the fear to find oneself in the kind of interpretational dead-end and to allow unspecified interventions bordering on fantasies.

b) There are some facts which can be absolutely obvious and which are not described in the formal way correctly. That is why it is devoid of any sense to interpret these facts as they contain some kind of uncertainty. It is not clear then if some particular real fact is interpreted (or a number of facts), or some "opinion" even if it is convincing, but which could arise thanks to different understanding and mental processes of the one who interprets them. It is also important to take into account those whom the producer of the text could affect or impress.

However all attempts to create a classification of combination of plot structures failed because the number of these combinations was practically infinite. From the methodological point of view, in order to classify the plot repetitions of different types they had to be singled out, distributed according to the levels and made into a list. But it is obvious that the number of possible plot combinations approaching infinity makes it impossible to do it.

\section{A list of Propp functions}

In the process of working with the plots which were found in the texts of the control and experimental groups we used the same principle that Propp used in his representations of fairy tales in the shape of consecutive "functions". Thus the parallel was drawn between Propp "functions" and the elements of the plot structures in the present work. The heuristic supposition was used as the starting point that in every concrete case a human being realizes a unique plot at the expense of the theoretically unlimited number of ways to combine the elements of plot structures (functions). Five elements of the plot structure were determined which were represented by the final list: exposition, introduction, the main body of the text, conclusion and coda. The combination of the elements which are received as a result as well as the length of the sequence of the combinations are entirely commanded by a human being. Then the elements of the plot structure were coordinated with the "functions of a fairytale" according to Propp.

1. Exposition: a description of the space and of the figures and things found there. It should be coordinated with the Propp "function i" (the starting situation) of a fairytale which did not enter the list of the functions (once upon a time). 
2. Introduction and 4. Conclusion as structure elements is coordinated with the whole number of functions according to Propp. They are signified by Propp as "dual". This is the list of the dual functions with numbers according to Propp.

1. Absence (the paired function is 20.Return). 2. Prohibition (the paired function is 3. Violation of prohibition). 4. Eliciting (the paired function is 5. Yielding). 6. Subterfuge (the paired function is 7. Collusion). 8. Harming (the paired function is 19. Elimination of the consequences; 30. Punishment: the enemy is punished). 12. The hero is being questioned, he is tried, he is being attacked (the paired function is 14. Supply: the hero gets some magic potion). 16. Struggle: the hero and the antagonist enter the immediate struggle. (the paired function is 18. Victory). 21. Persecution. (the paired function is 22. Salvation). 23. Unrecognised return. (the paired function is 27 . Recognition). 24. Unfounded attractions: the appearance of the fake hero. (the paired function is 27 . The recognition of the genuine hero; 28.Unmasking of the fake hero). 25. The hard task. (the paired function is 26. Solution).

Propp's terminology is mostly consecutive; in relation to dual functions it shows some fluidity: "insufficiency", “doing harm","misery" and others - these are definitions not only for the left parts of the dual functions, but one and the same function is sometimes called in different contexts by different names. Probably this reduction of the terminological meaning was caused not by the editor's carelessness of the researcher who was extremely attentive to details in other cases but by the absence of the possibility of determining the role of similar text events with the help of the means of the natural language in the same way.

Having made an attempt of generalization of the semantics of these functions with help of meta-language approaches which were unknown in the 20ies of the $20^{\text {th }}$ century we got such "meta-metalanguage" definition introduction in the whole of many-sidedness created by Propp: "something bad is happening = something the hero does not want to happen". It is easy to see that there are many similar events in a fairytale and each of them ends with conclusion, which on the meta-language level can be formulated as "there is an end to the bad = the hero did (got) what he wanted".

Thus in the structure element 2. introduction just like in a number of Propp functions given above there are "insufficiency", "misery", "doing harm", that is "something bad" and in the structural element 4.conclusion this "something bad" is either compensated in the dual row in the Propp functions or becomes "victory", that is "ceases to be", or is acknowledged as impassable and becomes a "defeat". It does not happen in a fairy tale but it is possible in spontaneous texts of the people who are experimented on, who are not tied up by the laws of the genre. We should point out that the sad conclusion differs from a happy one only by one thing, it depends in which part of a story the author decided to put a full stop. A fairytale should be told to the end - up to the conclusion where as in the story told by a client about some particular event the full stop is often put immediately after the introduction ("insufficiency", "misery", "doing harm"). The main body which chronologically connects the introduction and the conclusion describes the acts of the protagonist who enters the confrontation with the "insufficiency". With Propp as a rule we do not see any confrontation as separate functions they, confrontation is not separated either from the introduction or the conclusion. E.g. function 16.Struggle is described in this way: the hero and the antagonist enter an immediate struggle. It is both the introduction (the hero "does not want the antagonist to exist") and the confrontation (the hero "applies efforts and acts"). 
Coda the fifth element of the plot structure is evidently coordinated with the last $31^{\text {st }}$ fairytale function - Wedding, which describes the enjoyment with a result of the Victory. The elements of the plot structure of the texts which we singled out can be considered similar to the Propp functions of the fairytale. "The structural plot elements" in the framework of the given research semantically reduced much more than the Propp "functions". But the difference in the degree of reduction in no way prevents the solution of the task - that is the creation of the index of the plot structures which looks like Propp index but which is actually built on an entirely new principle. That is the new principle presupposes indexation not of the plot structured as a whole but the structural elements.

Some texts of the people attempted to commit suicide allow to bring out the principle of indexation of plot components, they will be the point of our investigation. "My main action is somewhere ahead. Sometime later when I am better and when I become a student of Medical school I will discover some medicine against cancer and AIDS. Everybody will be grateful to me for the salvation of the humanity from these horrible diseases - my kin and the people I do not know...(and further there are one and a half pages of the descriptions of material and communicative benefits which the author will get as a result of his popularity)". This text generated by the 43 year patient who has secondary education, she does not work and there were three attempts of suicide in her medical history. A young man 27 years old (secondary education, works as a delivery man, there were three attempts of suicide in his medical history), generates the following text: "Some time later I will manage to get a very highly paid job at some prestigious company. I will be paid no less than 7 or 8 thousand that is why I will be highly esteemed. For some particular job advances I will be paid bonuses equal to my 12 month salary..., (and again there is a description of the communicative and material benefits from what has been done, which are three times as much as his own job "achievement"). After a very short exposition (My main achievement is all ahead) there is an introduction (1) which contains some "insufficiency" (now I am not feeling very well..., as yet I did not have enough power to master my wish to drink..., Now my work does not satisfy me and it is badly paid...). This "insufficiency", as well as a number of other things which are not verbalized in Introduction(1) are successfully compensated for in the future (Not now but afterwards, when I feel better and when I have a secondary education certificate..., When they cure me so that I will not have any wish to drink and my professionalism will be really highly valued..., when I can find another job and also find many new friends...). The body of text (1) which in the normal syntax of the functions should be found between introduction(1) and conclusion(1), is not there (that is there is no talk about it). But immediately after Introduction(1) follows introduction (2). Here the benefits of victory: wealth and objects which were acquired thanks to it as well as fame, admiration of the people who surround him, love and the respect of new friends are described in detail and it takes about 2 thirds of the text volume. The presence of Conclusion (2) indicates another omission - absence of Introduction(2) which definitely reconstructs the "insufficiency" of money, things, fame admiration and friends. The characteristic peculiarity of these texts consists in two regular omissions: the refusal of describing the confrontation of the protagonist with "insufficiency" 1 which is an obstacle and a refusal to speak about the main "insufficiency" 2. Formally common for all the texts produced by the people who attempted suicides is the plot structure which can be presented as: $\mathrm{E}->$ $\mathrm{Z} 1$-> R1 -> R2 $->1$ and 2: $\mathrm{Z} 2=0 ; \mathrm{T} 1=0 ; \mathrm{T} 2=0$. The syntax of the texts generated by the people 
who have attempted suicide can be identically represented as a formulae: $\mathrm{E}->(\mathrm{Z} 1) \&(\mathrm{Z} 2=0)$-> $(\mathrm{T} 1=0) \&(\mathrm{~T} 2=0)->\mathrm{R} 1->\mathrm{R} 2->\mathrm{K}$. In the texts of the control group there are sometimes similar plot structures but they are varied both by preterition and syntax. It is easy to see that in the texts of the people who attempted suicide defeats are thoroughly concealed even if they are not quite obvious, and as to acts of confrontation, which are obvious both in the outer and the inner space, they are also omitted.

The characteristic omissions of the researched texts of the people who tried suicide is possible to interpret as a consecutive revelation of shame, weakness and loneliness which are accounted for by the highest degree egocentrism. It is just the shame that makes the author of the texts particularly omit "insufficiency" of Introduction(1) and refuse completely to verbalize the "insufficiency" of Introduction(2).

The authors may drop a word about the insufficiency only in the following Conclusions. But particularly important are two omissions in the Body of the text. The description and consequently the consideration, and the emotions following the confrontation with a problem become unbearable for the authors while confrontation 1, connected with the “outer" problems (disease, alcoholism, lack of education) is such that it can be imagined - some time in the future but confrontation 2 connected with existential problems is beyond conceiving and cannot be solved from the inside: these problems should be abolished on their own. In the texts of the control group there were no complete repetitions of the plot scheme of the experimental group, and as was expected there could not be found completely coinciding plot schemes inside the control group proper.

Thus thanks to the successful taxonometric approach omissions can be revealed and partially reconstructed, and we could arrive at the proof of the interpretation of this factor from the point of view of the contents.

Following this interpretation an entirely fantastic parallelism between a fairytale and the text of text techniques can be explained. What Propp thought to be the specific character of only a fairytale is in a fact the general property of any text - from "Once upon a time there was a poor knight" up to the instruction to the coffee grinder. These are constant subconscious returns to the unsolved or hardly solved problems of the existential character.

In other words whatever we are talking about except what is really said consciously we many times repeat at different levels: "That is my space, time, identity, freedom, loneliness and death - and that is how I am trying to defend myself from them".

\section{Conclusions}

The comparison of formalized up to plot structures of the texts of the experimental and control groups results in the following conclusions: From the theoretical methodological point of view the comparison allowed to operate with the concepts of complete and incomplete similarity of texts. The similarity of plot structures according to their type, according to the syntax of the functions and according to the omissions could be considered as complete similarity. Similarities on at least one of the suggested criteria should be considered incomplete similarity. The absence of incomplete similarity will be considered incompatible. From the clinic-psychological point of view the comparison of formalized plot structured is an effective diagnostic instrument which allows with the high degree of precision on the basis of the kind of the text to make suppositions about the inclination of the author of the text to come out of the frustrating situation resorting to autoagression. It should be noted that the diagnosticum described satisfies the criterion 
of sufficiency but not of necessity. In other words, if a text investigated with the help of the diagnosticum described demonstrates a specific plot scheme with two omitted confrontations in
$\mathrm{T} 1$ and $\mathrm{T} 2$ etc., then its author should be referred to the risk group, if this conditions is not realized then the inclination or disinclination of the author to suicidal behavior remains unclear.

\title{
References
}

Heidegger Martin. (1962). Being and Time. [Sein und Zeit]. SCM Press, 589 p.

Novikova-Grund M. W. (2014). Unikalnaya kartina mira individa i ieio otobrajeniye na teksty: na primere tekstov ludey, sovershivshih riad suitsidalnyh popytok. [The unique picture of the world of man being and its mapping in the text: by the example of texts of the people committed several suicide attempts]. Moscow, Lev, 188 p.

Jakobson, R. Linguistics and Poetics. (1960) Cambridge, MA: M.I.T. Sebeok, ed., Style in Language, Press, 377 p.

Schneider, Kirk J., May, Rollo. (1995 ). The Psychology of Existence: An Integrative, Clinical Perspective. McGraw-Hill, Psychology, 330 p.

Propp V. (1968). Morphology of the Folktale. University of Texas Press, 158 p.

Irvin D. Yalom. (1980). Existential Psychotherapy. N.Y., Basic Books, 524 p.

\section{Психосемиотический подход}

\section{в психолингвистике.}

\section{Анализ вербального материала \\ как способ воссоздания индивидуальной \\ картины мира человека}

\author{
М.В. Новикова-Грунд \\ Российский государственный гуманитарный \\ университет \\ Россия, 125993, Москва, Миусская площадь, 6
}

В современной психологической традиции наблюдается драматическое расхождение между экспериментальным доказательным исследованием и психотерапевтической практикой. Это связано с тем, что такие важнейшие в экзистенииальной и гуманистической психотерапии элементы бытия, как «картина мира индивида», «свобода», «одиночество» и др., являются семантически размытыми понятиями и поэтому оказываются недоступными для экспериментальной проверки и для традииионных математических методов. Однако их формализация и операционализация все же возможны. С помощью психосемиотических методов удалось показать, что картина мира индивида не является метафорой, а реально существует и последовательно отображается на тексты, письменные и устные, порождаемые этим индивидом. Анализируя тексты с помощью спеииально созданной формальной процедуры, оказалось возможным воссоздать модель картины мира автора этих текстов, причём формализация сводит к минимуму множественность и произвольность интерпретаций, а достоверность проверяется с помощью несложного математического метода, использующего комбинатори- 
ку. Результатом этого стало возможным обнаруживать в тексте умолчания и в ряде случаев реконструировать их (с оценкой погрешности), что помимо теоретического интереса открьвает продуктивные новые стратегии в психотерапии.

Ключевые слова: психолингвистика, семиотика, синтаксические структуры, парадигматика и синтагматика, экзистенциильные проблемы, повторяющиеся сюжетные структуры, психотерапия, умолчания.

Научная специиальность: 10.00.00 - филологические науки; 19.00.00 - психологические науки. 